\title{
World's Fastest Supercomputer Picks COVID-19 Drug
}

\author{
Zameer Shervani $^{*}{ }^{(0)}$, Intazam Khan ${ }^{2,3,4}$, Tasrina Khan ${ }^{5}$, Umair Yaqub Qazi6 \\ ${ }^{1}$ Nanomaterials Production Division, Food and Energy Security Research and Product Centre, Sendai, Japan \\ ${ }^{2}$ Department of Neurology, North Shore University Hospital, Northwell Health, Manhasset, NY, USA \\ ${ }^{3}$ Department of Neurology and Neuroscience, Weill Cornell Medical College, New York, NY, USA \\ ${ }^{4}$ Flushing Hospital Medical Center, Flushing, NY, USA \\ ${ }^{5}$ Biology Department, University at Buffalo, Buffalo, USA \\ ${ }^{6}$ Chemistry Department, College of Science, University of Hafar Al Batin, Hafar Al Batin, KSA \\ Email: ^shervani.nanotek@gmail.com
}

How to cite this paper: Shervani, Z., Khan, I., Khan, T. and Qazi, U.Y. (2020) World's Fastest Supercomputer Picks COVID-19 Drug. Advances in Infectious Diseases, 10, 211-225.

https://doi.org/10.4236/aid.2020.103021

Received: September 3, 2020

Accepted: October 11, 2020

Published: October 14, 2020

Copyright $\odot 2020$ by author(s) and Scientific Research Publishing Inc. This work is licensed under the Creative Commons Attribution International License (CC BY 4.0).

http://creativecommons.org/licenses/by/4.0/

\begin{abstract}
We have demonstrated the application of the world's fastest supercomputer Fugaku located in Japan to select the COVID-19 drugs and stopping the pandemic spread. Using computer simulation out of 2128 potential drug candidates, the world's fastest supercomputer picked 30 most effective and potential drugs. Twelve of them are under clinical trials outside Japan; some are being tested in Japan. The computer reduced the computation time from one year to 10 days when compared to second superfast computer of the world. Fugaku supercomputer was employed to know the behavior of airborne aerosol COVID-19 virus. 3Cs were suggested: avoid closed and crowded spaces and contacts to stop the pandemic spread. The progress in vaccine development and proper use and type of mask has also been described in this article. The article will benefit greatly to stop spreading and treating the pandemic COVID-19.
\end{abstract}

\section{Keywords}

COVID-19 Drug, World's Fastest Supercomputer, Fugaku Supercomputer, COVID-19 Treatment, COVID-19 Prevention

\section{Introduction}

The daily new cases of the COVID-19 pandemic are on the decline marginally in the US and Russia. The number of reported cases in the US decreased [1] from a peak 78,586 (July 24) to 42,843 (August 29). In Russia, daily novel coronavirus cases reached a maximum of 11,656 on May 11. Afterward, showed a continuous 
decrease and now stands 4941 cases reported in a single day on August 29. The daily coronavirus cases curve looks like decreasingly flattening [2] in Russia. The bars of the daily COVID-19 cases reported in Brazil do not show any regular pattern of declining or rising. The reason is not known. The number of coronavirus cases reported per day in Brazil peaked 70,869 (July 29) after 5 days cases decreased substantially to 17,988 (August 3) again increased to 54,923 (August 11) after 8 days then dipped to 22,365 (August 16) in 8 days. Latest on August 29 (in a single day) the number of coronavirus cases in Brazil was [3] 34,360 with no regular prediction. The situation is grim in India where the daily cases are on the rise. On June 15, there were 10,243 new coronavirus cases reported in a single day since then a continuous daily increase in the number of cases reported and the latest on August 29 (in a single day), the number was 78,472 [4]. In the whole world, the total number of COVID-19 cases reported, since the pandemic has occurred, by August 30 reached 25,323,189 (more than 25 million) and the deaths reported were 849,002 . Though, the daily number of cases reported in the world for the period July 24-August 28 has attained a plateau and stands 0.28 million [5]. This plateau value of pandemic cases ( 0.28 million per day) is when limited activities or no activities are going on in countries all over the globe. The countries are locked down or semi-lock down conditions such as schools are closed and limited economic activities are in place. We can not predict the pandemic spread when all activities become normal. The number of COVID-19 cases may increase, remain the same or show a decrease.

In our previous two previous articles [6] [7], we have described in detail very recent and useful information related to COVID-19 detection, treatment, and recent updates of vaccine developments. The efforts made and success achieved by different companies located in various countries the US, Britain, Germany, Russia, Indonesia, China, India, and Japan have been described [6] in detail to eradicate the COVID-19 pandemic from the globe. The contribution of the governments, doctors, health care workers, and administrative staff to contain the pandemic has been applauded. In this article, the application of the world's fastest supercomputer Fugaku in selecting the COVID-19 drug and method of containment has been discussed. Apart from the above, the progress in treatment by drugs and antibodies and vaccine progress in phase 3 have also been mentioned.

\section{Results and Discussion}

\subsection{Application of the World's Fastest Supercomputer in COVID-19 Treatment and Prevention}

Fugaku, the world's fastest supercomputer installed in Japan selected [8] dozens of suitable COVID-19 drugs from two thousand candidates. The drugs were picked based on selective bonding between the virus proteins and the drugs. Selected drugs are the best fit to bind with novel coronavirus proteins which are responsible for infection and virus growth. The drug binds with the virus proteins and inactivates it before the virus causes the symptoms. The computer was 
jointly developed by Riken and Fujitsu Ltd., Japan. The computer has the speed to perform 415 quadrillion computations per second. With maximum speed, it took 10 days for simulation to select the dozens of drugs from 2128 existing drugs that bind fit to virus proteins. The drugs which are already undergoing the trials outside Japan were also picked by the Fugaku supercomputer. Apart from the drugs which are under trials abroad, the computer suggested more candidates which could not get the attention of researchers for treating COVID-19. More of COVID-19 potential drugs will undergo clinical trials after obtaining the permission of the drug makers. Using the Fugaku supercomputer, the time needed to find the best suitable drug by simulation will become short of few days than one year other supercomputers will take to find an exact treatment of COVID-19. The supercomputer has proven the highest credibility as it is capable of performing simulation for a nuclear explosion, climate change, and damage an earthquake or tsunami can do. Now it is being used in finding novel coronavirus treatment. Kyoto University professor Yasushi Okuno, a specialist in computational science for pharmaceutical research, suggested [9] names of 30 most effective drugs for COVID-19 treatment. His selection of drugs is based on the computations conducted by the Fugaku supercomputer. Out of 30 drug candidates, one of the drugs is most effective. This drug was not known before and now it is under clinical trials. Negotiations are going on with more drug makers to put their products for clinical trials. Anticancer agents and common cold medicines were found to bind with SARS-CoV-2 proteins. A potential drug must bind and stay longer in keyhole spaces of the virus proteins to be more effective. The 12 drugs which are under testing outside Japan are the highest best fit to bind with virus proteins as per the supercomputer simulation. The other preferred drug is the antiparasitic drug Niclosamide. One Japanese drug was found a second best fit but the drug name was not disclosed due to patent rights infringement. The protein which is selected for simulation is SARS-CoV-2 main protease. The main protease of the virus is the enzyme which is used to make copies of the virus in infected person. By the end of summer, more COVID-19 virus proteins will be put for computer simulation to find more drug candidates. Fugaku supercomputer took just 10 days to scan a total of 2128 drugs, a much shorter time than its predecessor could do in a longer time of one year.

Japanese supercomputer Fugaku was employed [10] [11] for simulation to know the behavior of airborne SARS-Cov-2 virus aerosol. Researchers concluded that the trains with limited numbers of passengers and open windows will reduce the airborne coronavirus spread. Floating virus particles infect the passengers when they breathe through the airborne transmission. Places must have ventilation and be less crowded. The Japan Committee for COVID-19 countermeasures adopted 3 Cs avoid closed spaces, crowded places, and close contacts. Implementing these $3 \mathrm{Cs}$ and cluster and contract tracing, Japan has controlled the pandemic just 19,000 COVID-19 cases and 977 deaths. A high concentration of airborne virus must be avoided by following the 3 Cs to stop spreading the pandemic. 


\subsection{Development of COVID-19 Drug}

Bonac Corp., a biotechnology startup in Fukuoka Prefecture of Japan has developed a drug and started [12] clinical trials on humans for COVID-19 treatment. The drug is expected to be ready in 2021. The company has developed a total of 72 probable drugs for nucleic acid medicines and tested them against novel coronavirus. It is a joint research project between the company and Fukuoka Institute of Health and Environmental Sciences, Japan. The research was going on since June 2020. Out of 72 candidates, 10 of them are proven-effective in significantly reducing the replication of novel coronavirus. Three out of 10 drugs have very high potency therefore, a very small dose is needed for the cure. These three drugs also have very high stability in the human body. One of the drugs has completed non-clinical tests and is ready to test on humans. The drug works on the principle of "RNA interference technology", to decompose genomic RNA of the coronavirus thus has strong antiviral effects against the virus to cure the disease. It is a RNA based drug that destroys the genomic activities of the virus so that the virus can not cause the disease in patients.

\subsection{COVID-19 Antibodies Treatment}

Apart from finding a suitable drug for novel coronavirus SARS-Cov-2, we describe another approach of treating COVID-19 patients with an antibody-based cocktail mixture. The antibody cocktail can work for prevention to stop novel coronavirus infecting the body and also as a treatment to cure if the virus started causing the disease. A British pharmaceutical company AstraZeneca has developed [13] an antibody-cocktail mixture to treat and prevent the COVID-19 disease. The antibody mixture AZD7442 consisting of two monoclonal antibodies was found safe when tested on 48 volunteers in the age group 18 - 55 years. The company will conduct the trials to test preventive and medical aspects of novel coronavirus infection. Hopefully, the final product will be available soon in the market after the successful completion of trials. The concept is monoclonal antibodies (mAbs) prepared from bio-sources in the laboratory mimic the naturally produced antibodies in the body when infection occurs. The company received \$23.7 million from the US government to complete the research and make the final product. The antibodies cocktail mixture will also have the potential to overcome the re-infection and COVID-19 virus resistance which is not possible by other therapies. The plasma therapy is another antibody-based treatment but it lacks preventive and resistance aspects of the COVID-19 disease. Antibodybased cocktail formulation development has importance since the AstraZeneca's COVID-19 vaccine will not get approval in the US until November the earliest possible.

\subsection{COVID-19 Reinfection and Suggestion to Vaccine and Drug Makers}

COVID-19 reinfection cases were reported from Belgium, Netherlands, Nevada 
(US), and Hong Kong (China) [14] [15] [16]. Recovered SARS-CoV-2 patients contracted the virus a second time. Immunity generated in the body after the first infection could not stop infection for the second time. Immunologists expect reinfection may not be as severe as it caused symptoms for the first time. That exactly happened in reinfection reported from Hong Kong. The person was found COVID-19 positive again after recovering from the first symptomatic infection but the second time remained asymptomatic. Therefore, reinfection can not be seen as a botheration for millions of people who have recovered from the disease. However, for vaccine developers, it must be taken into consideration to give a booster dose or make vaccines that can prevent reinfection. In Nevada (US) reinfection case, the person became symptomatically sick again after 48 days justifies the observation of decreasing the antibody amount with time at the rate of half-life of antibodies was 36 days in SARS-Cov-2 recovered patients. Only $16.7 \%$ of recovered patients were found to have strong antibodies neutralizing capacity after 90 days of the onset of COVID-19 infection and no antibodies were present in many patients [6]. But the Nevada case of reinfection with symptoms is only one in millions, more data will be obtained in the coming days of reinfections. The depletion of SARS-Cov-2 antibodies in a few months is not a bigger issue as $\mathrm{T}$ cells (the cells which have the memory to generate antibodies) of SARS-Cov-1 remained [6] for 17 years. But the vaccine makers must confirm the existence of $\mathrm{T}$ cells or antibodies for longer duration against SARS-Cov-2.

\subsection{Progress in Vaccine Development}

Moderna's vaccine mRNA-1273 induced [17] immune response in older (age 56 and above 70) and younger (age 18 - 55) participants equally against COVID-19. The trial is in phase 3 for safety data on a large number of participants. One shot of the vaccine has 100-microgram content. A total of 13,000 participants registered for the trail. The participants were Alaska Native, Native American, Black, and Latino they were hard hit by the pandemic. Pfizer Inc on the other hand has enrolled 11,000 subjects for its vaccine testing on Black or Latino. Moderna is accelerating the trial to show the results for the Presidential election this year in the US which is also good to benefit the world's population. Moderna's RNA based vaccine must be shipped and stored at cold deep freezing temperature. The vaccine will be distributed in vials each vial will have enough content for 10 doses. Moderna is working to make the vaccine stable at a temperature where cooling is not needed. The COVID-19 vaccine is Moderna's first product in the inoculation segment. The company has received a $\$ 1$ billion grant from the US government to speed up the vaccine delivery for mass inoculation. Moderna has received an order of $\$ 1.5$ billion from the US.

\subsection{Kinetics of Antibody Development in COVID-19 Patients and Antibody Based Testing}

Long et al. [18] reported the kinetics of antibody response to SARS-Cov-2 in 285 patients. In 19 days, immunoglobulin-G (IgG) was formed in all the patients af- 
ter the onset of symptoms. Both IgG and IgM titers reached a plateau in 6 days. Complete serological investigation and study of kinetics are necessary for testing and identifying asymptomatic patients. Patients developed positive virus-specific IgG to a $100 \%$ level in 17 - 19 days and it took 20 - 22 days to develop IgM to a level $94.1 \%$ after the onset of the symptoms. As a total in the first 3 weeks of the onset of symptoms COVID-19 virus specific IgG and IgM titers increased. IgM decreased slightly after 3 weeks. IgG and IgM titers in severe patients were more compared to patients who were not severe. The authors have claimed that COVID-19 virus specific antibodies IgG and IgM detection are important to support RT-PCR RNA detection testing when negative RT-PCR results are obtained. The study will benefit in the survey of asymptomatic infection. Serological testing will save more expensive RT-PCR tests and help to identify COVID-19 cases on a large scale in a short time to stop spreading the disease. The application of serological application was verified in a small sample size of 7 cases which showed negative RNA RT-PCR test had no symptoms showed positive IgG or and IgM.

\subsection{Importance of Face Masks in COVID-19 Pandemic: The History of Face Masks, How to Use It, and Type of Masks Preferred Scientifically}

On April 7, Japan declared a state of emergency for 7 prefectures initially but on April 16, the state of emergency extended to the entire nation when infection reached 10,000. On May 4, the state of emergency extended till May 31. But on May 14, the state of emergency was lifted in 39 out of 47 prefectures much ahead of the expiry date. The early lifting of the state of emergency was due to the criteria met when infection fell below 0.5 new cases per 100,000 people in the past week [19]. The number of new corona cases around May 14 (May 15) was lowest in Japan and the United States had the highest, the order was [20] the United States $>$ Russia $>$ Britain $(=$ Spain $)>$ Italy $>$ Brazil $>$ Germany $>$ France $>$ Peru $>$ India $>$ Japan. In the latest comparison plot available of July 12, the order of pandemic cases was the United States $>$ Brazil $>$ India $>$ Russia $>$ Japan. Such a low number of cases in Japan, despite there was never a forced lockdown however a voluntarily limited state of emergency for a short period, has been due to long existing mask culture, in the Japanese society all the time 365 days of the year, prevailing when Japanese use masks for mild infections of common cold and cough, fever in influenza seasons especially when weather changes. The use of masks in public or private transport, offices, public places, hospitals, markets, schools, restaurants, bars, and among own family members is very common as a habit and is a part [21] of Japanese culture. The use of masks contained the COVID-19 pandemic in Japan which was not the case in any other country where spread was unstoppable. Mask-wearing habit in Japan was the reason that avoided the heavy coronavirus deaths as occurred in other parts of the world, experts said [22]. Using masks has become a part of everyday life in Japan since the outbreak of the COVID-19 pandemic happened. As of May 27, 2020, Japan 
recorded nearly 16,000 cases of COVID-19 infections and 850 deaths, the lowest among the major world economies in the Group of Seven. A combination of PCR and antigen testing is underway to control the pandemic. Japan has a long historical experience [21] using face masks to fight against the pandemic like COVID-19. Japanese people believe "eyes speak as much as the mouth". Japanese people's affinity for face masks can be traced in the last centuries as the part of the custom which saves Japanese lives from COVID-19. A large number of deaths in the United States where using masks became a political issue and was seen as taking away the individual's liberty and freedom.

In Japan when COVID-19 cases climbed there was a nationwide shortage of masks that made headlines. The companies which were making other products such as sweaters started making masks and vending machines were used to fulfill the demand. Yamashin-Filter Corp., a filters manufacturer for construction machinery, started using "nanofiber" to make masks. Yamashin-Filter Corp, claimed the fibers used to prepare masks to have a diameter in the range $0.2-0.8 \mathrm{mi}$ crons while the other company's fibers' size is much thicker of 3 microns. The layered masks prepared has a mesh size of filter which is fine enough to stop 0.1 microns COVID-19 virus entering the mouth and nose. The company makes masks in Japan to ensure the availability of masks in the Japanese market. Another Japanese company Yonex Co. maker of sports gear also began supplying masks. Health officials said masks serve the purposes of capturing airborne particles and thus stopping virus transmission. A proper mask is necessary which leaves no open space and fits properly covering the mouth and nose. A filter in a mask is essential that can filter stop a particle of size 0.1 microns. N95 masks or similar masks that can meet this requirement are good to stop virus spread. The look of the facial features of a person using the mask is not important. Aperture or filters-valves type masks reduce the mask's ability to stop the pathogens and breathing efficiency is also less because of reduced surface area, therefore they are not recommended for coronavirus COVID-19. N95 layered pollution masks are good to stop the virus spread. On branded online stores like amazon mostly efficient N95 layered masks are for sale. Filters-valves type is not in the store. In Japan, masks became acceptable in the first SARS-Cov-1 virus in 2003 which also spread from China. Japan was spared largely in that pandemic with no death. Covering the mouth with paper or cleyera leaves was part of the shrine's ritual during the Edo Period (1603-1868) to prevent one's unclean breath from damaging religious rituals. These shrine rituals penetrated later in a large population in general. However, the modern history of masks begins in the Meiji Era (1868-1912) when masks were used for mine, factories, and construction workers. The practice continued in World War I when masks made of leather, velvet, and other materials were used. In Spanish flu, masks became everyday products for all when the flu killed several million people around the globe in the year 1918-1920. Spanish flu had the infectious nature of the virus. People started using masks which helped them protecting from influenza. In Japan, masks were in short supply in World War II when raw materials were reserved 
for the military. Then Japanese common man starting using masks made from cheaper gauze attached to strings became popular. This is all about the unique evolution of masks in Japan. Masks are safe for oneself and also do not infect others.

Government advisory [23] warned not to use N95 masks which have valves. Masks with valves are good for pollution and allergies as they filter bad air to go inside but for COVID-19, masks with valves are the problem. Valve allows infected air to out. If an infected person is in the crowd, he or she will infect the others. One way valves do not stop virus transmission. Thus layered face masks with a wire lining to fit the nose shape cover both mouth and nose offer complete protection for oneself and others. Flexible layered masks that cover both mouth and nose properly, are good. Space must not be left to stop un-filtered air being sucked inside the nose and enter the mouth. Masks must be disposed following the virus de-contamination procedure the same as for other protective suits. Re-usable masks must be sanitized and disinfected. For washable masks, proper washing with laundry detergent will break the virus into components thus sanitizing the mask for re-use. Washing with detergent is the same as removing sticky oils and fats assemblies from cloths by breaking them and then components dissolved in water and go away with the detergent water solution to drainage. Masks must not be shared to avoid transmission. A comparative study was done [24] to identify if the common fabric materials are useful to protect from the influenza virus like aerosols of the size $20-1000 \mathrm{~nm}$. The penetration level of common materials cloth masks, sweatshirt, T-shirt, towel, a scarf was very high $(40 \%-90 \%)$ against aerosols. It was concluded that only N95 masks can offer $98 \%$ protection. For good protection, Bacterial Filtration Efficiency (BFE) and Particle Filtration Efficiency (PFE) of more than 95 must be used or as suggested by health officials. A good mask is composed of multilayer nonwoven melt-blow fine fabric. A range of masks: makeshift masks, gauze masks, non-woven masks, dust masks, and N95 masks were tested [25] in a laboratory to know the penetration of airborne COVID-19 virus like structures. If a proper mask was not used in a proper method leaving space between the face and masks, the leakage rate will be $100 \%$ leaving no protection against the virus. Therefore, using a proper mask in a proper method, as described above, only can give full protection against the virus. Figure 1 is an example multilayered disposable face mask, if used properly it will give more than $95 \%$ protection to the user from inhaling the SARS-Cov-2 virus and stop releasing infected user's virus in the air.

\subsection{Mechanism of Infection (Immune Response, the Concept of Asymptomatic and Symptomatic Patients, and Kids' Immune System)}

Till April 22, 2020; 2.5 million people infected and 170,000 died of the SARSCov-2 virus. Here we look at the reason why some become sick and die and others do not develop any symptoms. Study shows $80 \%$ or more who have virus show 


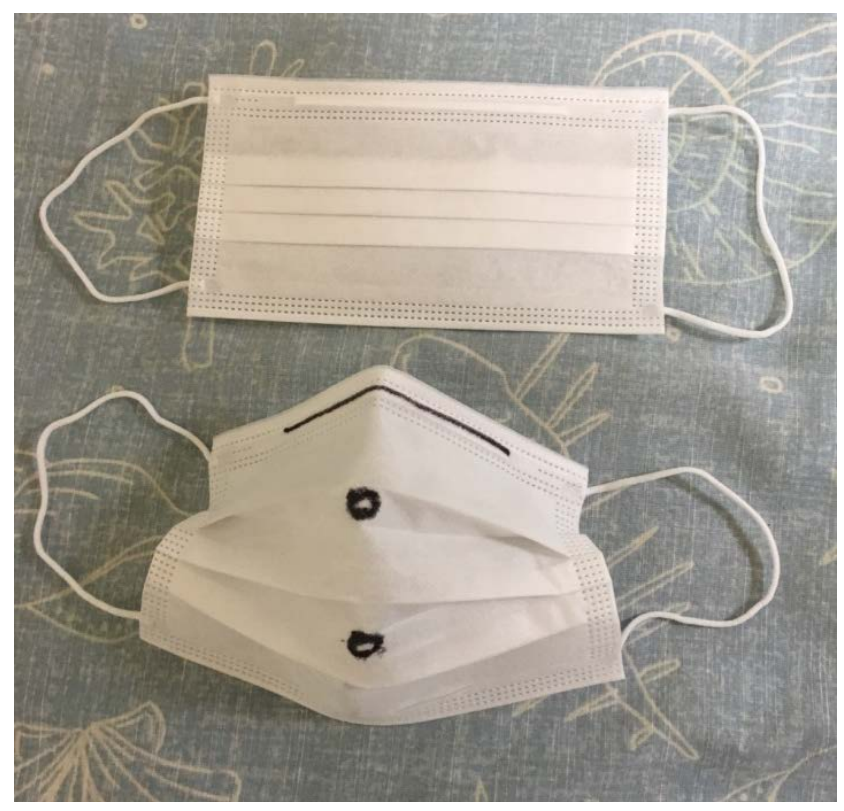

Figure 1. Scientifically recommended multi layered disposable face mask for COVID-19 that gives more than $95 \%$ protection from inhaling and releasing the virus in the air. The black line drawn by the pen is the wire to take shape of the nose and dots are the locations of the nose and mouth. Covering the nose and mouth both are necessary. A non-printed white or single light color mask is recommended. No space must be left between the mask and face.

very mild or no symptoms at all are "silent carriers". To lock onto the inner linings of body parts stomach, gut, kidney, heart, and lungs the virus's outer shell gets attached to the matching protein of the body called receptors are known as ACE2 in a lock and key arrangement. After reaching inside the body parts, RNA of the virus multiplies or makes copies. To cause harm or disease virus can take up to two weeks in the incubation period. A person who has strong immunity, virus multiplication stops, and virus concentration decreases to nil. Children have a natural strong adoptive immune system that stops virus causing any harm to them and viral load decreases and finishes more quickly. Apart from children, healthy adults who have a strong immune system respond to the virus attack faster and finish the invading SARS-Cov-2 virus. In the above cases, the COVID19 virus can be finished at the entry part of the body by the physical barrier such as mucous membrane in the soft linings of the nose and throat before it enters deep inside the body. If the virus is not eliminated at the entry point then it enters inside the body parts. Through the trachea, the virus enters the lungs where it locks with ACE2 receptors inside the lungs and starts making copies. The immune system of the body fights with the virus in the process large amount of fluid generated that fills the lungs air cavities and decreases the air purification capacity of the lungs. Oxygen intake to the blood and removal of carbon dioxide process slows down. Symptoms of pneumonia fever, cough, sputum, and breath shortening occur. Excessive immune response and prolonged infection cause a "cytokine storm". The "cytokine storm" is a dangerous overreaction by the im- 
mune response causes the inflammation and organ damage and finally death [26].

To give input in the debate if the schools must be open in the fall in the US, here are some data [27], of COVID-19 in children. Research showed [28] [29] a large amount of coronavirus was found in children younger than 5 years old. The swab tested showed upper respiratory tracts of young children had a viral load 10- to 100-fold more than adults. Researchers, however, reported the viral load was of viral nucleic acid (viral RNA), not an infectious virus (infectious RNA). Meaning that it is not clear whether children can spread the virus. Further investigations are awaited by other researchers. Though, it is a matter of big concern for daycare centers and schools, the presence of a large amount of viral nucleic acid in children younger than 5 years. When it is the turn for vaccination this large population of younger children must be taken into consideration. For the development of a vaccine or COVID-19 specific treatment, we need to know facts and data available on the COVID-19 SARS-Cov-2 virus. Young children mostly do not show severe virus infection as noticed by doctors around the world. Children are less susceptible to novel coronavirus compared to adults. ACE2 receptors are proteins [30] that provide an entry point for coronavirus to enter and infect human cells and subsequently causing the disease. ACE2 protein enzymes generate small proteins and control the cell functioning in the body. They are found in the body parts the kidneys, liver, gastric intestinal tract, lungs, heart, blood vessels. It is on the surface of tissue linings. ACE2 receptors are less in small children than adults. The study was conducted [31] on 305 patients who were 4 - 60 years old, results were ACE2 receptors were least in small children than older children than adults. Studies conducted in Iceland, Netherland, Australia, and China, in all fewer children got infected compared to adults. Rapidly developing immune systems in children can fight pathogens like novel coronavirus COVID-19 is the reason children are least infected.

\subsection{A Case Study of COVID-19 Fatality Rate, Active Cases, and Patients Discharged from Hospital}

As on July 31,2020 , reported [32] fatality rate of COVID-19 in India was $2.18 \%$ (the lowest globally) among the total active cases 5, 45, 318 in which $1.61 \%$ were in ICU (intensive care unit) and $2.32 \%$ were on oxygen support. It came out to be $3.93 \%$ needed serious hospitalization. The number of patients on ventilators was just $0.28 \%$. On this date, the recovered number of patients reported was one million. This makes the recovery rate of $64.54 \%$, the highest globally. Only $33.27 \%$ (nearly one third) of the COVID-19 patients needed medical care. The report suggested the fatality rate recently declined. It was higher earlier. The reason for decreasing the fatality rate is because doctors have understood the disease as time progressed with new cases reported every day. Also, the public has become aware of the disease taking preventive measures such as using face masks and keeping physical or social distancing. The recovery rate was less 
48.3\% in the first week of June and $25.6 \%$ at the end of April [33]. The fatality rate was also higher at $3.3 \%$ in June. India's fatality rate is lowest next to Russia (1.6\%). World's average death rate is $4 \%$. The countries US, Brazil, Iran, Mexica, and the UK have fatality rates $3.5 \%, 3.6 \%, 5.5 \%, 11 \%$, and $15.3 \%$, respectively. In India, more than one million people have recovered until July 30 .

By August 2 [34], the total number of COVID-19 cases in India reached 1.7 million marks with a tally reached 54,735 cases in a day and 1.1 million reported recovered. Whereas, around the same date (August 1) the US reported 61,262 new coronavirus cases in a single day [35]. The US is the hardest hit country so far reported more than 4.6 million cases and 154,319 fatalities.

\subsection{Treatment of COVID-19}

Japan health ministry has approved to use dexamethasone a steroid drug for the treatment of coronavirus patients. This is the second approved drug in Japan. The first one was remdesivir which was approved in May 2020. The drug dexamethasone is inexpensive and easily available. It is already in use to treat a number of diseases including lung infection. In Japan, it is on the list of drugs covered by insurance companies. The study conducted [36] by the University of Oxford showed 2100 COVID-19 patients were given dexamethasone for ten days, the number of deaths reduced by a third for the patients who were on ventilation and for those who were only on oxygen death reduced to a fifth. National Institute of Health, US and World Health Organization (WHO) also recommended the drug for severe COVID-19 patients who have fewer chances of survival. Japan approved [37] remdesivir an antiviral drug for the treatment of COVID-19 patients. The drug remdesivir is a brand of Gilead Sciences (American pharmaceutical company). Remdesivir is the first drug approved by Japan for SARSCov-2. In USA, remdesivir was approved already for emergency use by the FDA (Food and Drug Administration). NIH (National Institutes of Health, US) found in a trial ramdesivir treated COVID-19 patients recovered in eleven days whereas the patients who were not treated with the drug took fifteen days to recover. However, mortality remained the same. In an Editorial [38], it has been reported that the experimental antiviral drug remdesivir was approved in haste. The report described the drug is not a miracle. The drug shortened the recovery time by four days in a trial of 1000 patients of COVID-19. However, it is not confirmed if the drug can save a life. The reported side effects were huge including kidney and liver damage.

\subsection{Important Developments Occurred during COVID-19 Pandemic}

Japan's Mitsubishi Heavy Industries Ltd. once more was successful [39] in launching the United Arab Emirates (UAE), the H-IIA rocket into Mars orbit. This is the first space mission to Mars undertaken by any Arab country. The probe "Hope" successfully separated from the rocket after one hour it was lifted. 
The rocket was launched from Tanegashima Space Center in Kagoshima Prefecture of Japan at 6:58 morning on July 20,2020. The orbiter was developed by $\mathrm{UAE}$. The probe successfully detached as monitored by the control room. Japan conducted such successful rocket launching before for South Korea, Canada, and UAE in years 2012, 2015, and 2018, respectively. The probe will study the weather of Mars from its orbit to know the possibility if human settlements are possible on the Red Planet Mars. Japan completing the project in difficult coronavirus crises has been applauded. UAE's ambition is to build the human settlement on the red planet within 100 years. UAE became [40] the first Arab country to make a nuclear power plant operational on August 1, 2020. All four units of the plant when become operational, the South Korean installed, the power plant can produce enough electricity for one fourth of the country's total requirement. The plant is absolutely for peaceful energy purposes. The reporter told the second Arab country Saudi Arabia is the next to acquire nuclear power generation technology. Just started nuclear power plant in UAE is known as the "Barakah" project was approved by International Atomic Energy Agency (IAEA) and the US to receive technical assistance and materials on the condition it will not do enrichment. UAE said natural gas and renewable sources were not enough to meet the country's electricity needs.

Energy demand decreased in European Countries (EU) during the coronavirus pandemic. For the first time, renewable power contributed more than fossil fuels. $27 \mathrm{EU}$ countries used 40\% [41] electricity from renewable sources while fossil fuels' contributed $34 \%$. The higher contribution of renewable energy resulted in carbon dioxide emission decrease by $23 \%$. This is the good news in the context of Europe which has the plan to spend billions of euros to recover from coronavirus crises. When industrial activities will resume in the post-coronavirus period the lower carbon dioxide emission will be seen as a footprint in EU development. The larger contribution of renewable energy than fossil fuel based generation is a milestone in Europe's history of the new world. Countries like Poland and the Czech Republic who mostly depend on coal as fossil fuel will also develop renewable energy resources. The output from hydro, wind, and solar power generation has increased in Europe recently. The priority is being given to renewable resources to supply electricity to the grid while fossil fuel based plants are switched off.

In comparison to Europe, the United States in contrast generated more than $62 \%$ of electricity from fossil fuels while the contribution of renewable energy remained low 18\% [42]. For the last 5 years, Europe has made huge progress in renewable energy generation, the production of electricity from coal was cut to half and replaced by wind and solar power. There is a $32 \%$ drop in electricity generation from coal across Europe. In March 2020, Austria and Sweden closed all coal fired power plants. Spain has already closed all coal powered plants. Germany reduced 31 terawatt hours of power generation from coal. This cut by Germany is huge since many countries' total electricity need is less than this 
amount in the EU and other countries outside Europe. The amount of electricity generated by wind and solar in Denmark, Ireland, and Germany accounts 64\%, $49 \%$, and $42 \%$, respectively. The cost of electricity produced by renewables sources is much cheaper (23 Euro/megawatt hour) in Germany than (40 Euro/megawatt hour) electricity produced by coal in Poland.

\section{Author Contribution}

All authors contributed equally.

\section{Statement of Human and Animal Rights}

No animal and human rights issues exist in this research. No animal or human experiments were conducted in this research.

\section{Authors' Qualification}

Zameer Shervani Ph.D., Intazam Khan, M.D., Umair Yaqub Qazi, Ph.D., Tasrina Khan B.Sc.

\section{Acknowledgements}

Zameer Shervani is grateful to his brother Fida Ahmad Khan of Bhamon.

\section{Conflicts of Interest}

The authors declare no conflicts of interest regarding the publication of this paper.

\section{References}

[1] Worldometer Covid-19 Data. http://worldometers.info/coronavirus/country/us

[2] Worldometer Covid-19 Data. http://worldometers.info/coronavirus/country/russia

[3] Worldometer Covid-19 Data. http://worldometers.info/coronavirus/country/brazil

[4] Worldometer Covid-19 Data. http://worldometers.info/coronavirus/country/india

[5] Worldometer Covid-19 Data. http://worldometers.info/coronavirus

[6] Shervani, Z., Khan, I., Khan, T. and Qazi, U.Y. (2020) Covid-19 Vaccine. Advances in Infectious Diseases. (In Press) https://doi.org/10.4236/aid.2020.103020

[7] Shervani, Z., Khan, I. and Qazi, U.Y. (2020) SARS-Cov-2 Delayed Tokyo 2020 Olympics: Very Recent Advances in COVID-19 Detection, Treatment, and Vaccine Development Useful Conducting the Games in 2021. Advances in Infectious Diseases, 10, 56-66. https://doi.org/10.4236/aid.2020.103007

[8] Japan's Fugaku Supercomputer, World's Fastest, Narrows down COVID-19 Drug Candidates. The Japan Times, July 4, 2020.

[9] Japanese Supercomputer Finds 30 Existing Drugs Potentially Effective to Treat COVID-19. The Mainichi, July 4, 2020.

[10] Japan Supercomputer Suggests Changes to Travel, Work amid Airborne Virus Threat. REUTERS, July 8, 2020.

[11] Japan Supercomputer Finds Ways to Nix Airborne Virus at Work and on Trains. 
The Japan Times, July 8, 2020.

[12] Japan Startup to Begin Human Clinical Tests for COVID-19 Drug in 2021. The Japan Times, August 25, 2020.

[13] AstraZeneca Starts Trial of COVID-19 Antibody Treatment. Nikkei Asian Review, August 25, 2020.

[14] Andrew Joseph, Scientists Are Reporting Several Cases of Covid-19 ReinfectionBut the Implications Are Complicated. STAT, August 28, 2020.

[15] Coronavirus Vaccine: With COVID-19 Reinfection Cases Surfacing, Do We Need to Revise Vaccine Approach? Timesofindia.com, August 28, 2020.

[16] Andrew Joseph, First Covid-19 Reinfection Documented in Hong Kong, Researchers Say. STAT, August 24, 2020.

[17] Moderna COVID-19 Vaccine Appears to Work as Well in Older Adults in Early Study. The New York Times, August 26, 2020.

[18] Long, Q.-X., Liu, B.-Z., Deng, H.-J., Wu, G.-C., Deng, K., Chen, Y.-K., Liao, P., Qiu, J.-F., Lin, Y., Cai, X.-F., Wang, D.-Q., Hu, Y., Ren, J.-H., Tang, N., Xu, Y.-Y., Yu, L.-H., Mo, Z., Gong, F., Zhang, X.-L., Tian, W.-G., et al. (2020) Antibody Responses to SARS-CoV-2 in Patients with COVID-19. Nature Medicine, 26, 845-848.

[19] Japan Lifts Coronavirus Emergency outside Tokyo, Osaka Regions. Kyodo News, May 14, 2020.

[20] Japan Data, Coronavirus Cases by Country. http://nippon.com/en/japan/-data/h00673

[21] The History behind Japan's Love of Face Masks. The Japan Times, July 4, 2020.

[22] Masks Helped Keep Japan's COVID-19 Death Toll Low, Says Expert Panel. The Japan Times, May 28, 2020.

[23] Government Issues Advisory against N95 Masks: Which Is the Best Type of Mask to Protect You from COVID-19? Timesofindia.Com, July 30, 2020.

[24] Rengasamy, S., Eimer, B. and Shaffer, R.E. (2010) Simple Respiratory ProtectionEvaluation of the Filtration Performance of Cloth Masks and Common Fabric Materials against 20-1000 nm Size Particles. Annals of Occupational Hygiene, 54, 789798.

[25] Naoya Kon/(Staff Writer), Cloth Face Masks Offer Zero Shield against Virus, a Study Shows. The Asahi Shimbun, July 7, 2020.

[26] Why Do Some People with COVID-19 Get Symptoms While Others Don't? Science Alert, 22 April 2020.

[27] Heald-Sargent, T., Muller, W.J., Zheng, X.T., Rippe, J., Patel, A.B. and Kociolek, L.K. (2020) Age-Related Differences in Nasopharyngeal Severe Acute Respiratory Syndrome Coronavirus 2 (SARS-CoV-2) Levels in Patients with Mild to Moderate Coronavirus Disease 2019 (COVID-19). JAMA Pediatrics, 174, 902-903. https://doi.org/10.1001/jamapediatrics.2020.3651

[28] Children Younger than 5 Years Could Very Well Be Carriers of Covid-19: Study, Health Shots, July 31, 2020.

[29] Explained: Why Does Coronavirus Impact Children and Adults Differently. Timesofindia.com, July 30, 2020.

[30] What Is the ACE2 Receptor, How Is It Connected to Coronavirus and Why Might It Be Key to Treating COVID-19? The Experts Explain. The Conversation, May 14, 2020 .

[31] Bunyavanich, S., Do, A. and Vicencio, A. (2020) Nasal Gene Expression of Angio- 
tensin-Converting Enzyme 2 in Children and Adults. JAMA, 323, 2427-2429. https://doi.org/10.1001/jama.2020.8707

[32] At 2.18\%, India's Covid-19 Fatality Rate among Lowest; Just 0.28\% Patients on Ventilator: Vardhan. The Times of India, July 31, 2020.

[33] Covid-19 in India: Recoveries Hit 10L, Fatality Rate 2.2. The Times of India, July 31, 2020 .

[34] Over 54,000 Covid-19 Cases in India in Single Day, Total Tally Crosses 17 lakh. The Times of India, August 2, 2020.

[35] US Counts 61,262 Covid-19 Cases in 24 Hours: Johns Hopkins. The Times of India, August 2, 2020.

[36] Japan Approves Dexamethasone as Second Drug for Coronavirus Treatment. The Japan Times, July 22, 2020.

[37] Juntaro Arai, (Nikkei Staff Writer), Remdesivir Approved as Japan's First Coronavirus Treatment, May 7, 2020.

[38] Editorial: Plusses and Minuses to Speedy Japan Approval of Remdesivir to Treat COVID-19. The Mainichi, May 9, 2020

[39] Japan Launches First Arab Space Mission to Mars. The Japan Times, July 20, 2020.

[40] Vivian Yee, U.A.E. Becomes First Arab Nation to Open a Nuclear Power Plant. The New York Times, August 1, 2020.

[41] Renewable Power Surpasses Fossil Fuels for First Time in Europe. The Japan Times, July 23, 2020.

[42] David Vetter, European Renewables Just Crushed Fossil Fuels. Here's How It Happened. Forbes, July 23, 2020. 